\title{
A Novel Tripartite Evolutionary Game Model for Misinformation Propagation in Social Networks
}

\author{
Xianyong Li $\left(\mathbb{D},{ }^{1}\right.$ Qizhi Li $\left(\mathbb{D},{ }^{1}\right.$ Yajun Du $\mathbb{D D}^{1},{ }^{1}$ Yongquan Fan, ${ }^{1}$ Xiaoliang Chen, ${ }^{1}$ Fashan Shen, ${ }^{2}$ \\ and Yunxia $\mathrm{Xu}^{2}$ \\ ${ }^{1}$ School of Computer and Software Engineering, Xihua University, Chengdu 610039, China \\ ${ }^{2}$ Sichuan Suitang Science and Technology Co., Ltd., Chengdu 610045, China \\ Correspondence should be addressed to Xianyong Li; lixy@mail.xhu.edu.cn
}

Received 20 November 2021; Accepted 31 December 2021; Published 19 January 2022

Academic Editor: Chenquan Gan

Copyright (C) 2022 Xianyong Li et al. This is an open access article distributed under the Creative Commons Attribution License, which permits unrestricted use, distribution, and reproduction in any medium, provided the original work is properly cited.

\begin{abstract}
Misinformation has brought great challenges to the government and network media in social networks. To clarify the influences of behaviors of the network media, government, and netizen on misinformation propagation, a large number of influence parameters are proposed for the three participants. Then, a tripartite evolutionary game model for misinformation propagation is constructed. According to the proposed game model, the expected payoffs of three participants are analyzed when they adopt different strategies. The evolutionary stabilities of the game model are also analyzed theoretically. Finally, the impacts of different parameters on expected payoffs of three participants are analyzed experimentally. Meanwhile, coping strategies of three participants under different conditions are given. The experimental results show that the proposed tripartite evolutionary game model can properly describe the influence of network media, government, and netizen on misinformation propagation.
\end{abstract}

\section{Introduction}

In social networks, misinformation propagation may bring adverse impacts on society or individuals who used the networks. Many researchers have found some effective ways to characterize the law of misinformation propagation and to further control misinformation propagation. To detect misinformation with a limited budget in online social networks, Zhang et al. [1] proposed two algorithms with minimum monitors. On real networks, their methods showed effective performance. To stop misinformation propagating to online social networks, Pham et al. [2] designed a PR-DAG algorithm to maximize misinformation restriction in the networks. Tan et al. [3] introduced an activation increment based on nodes' different statuses. They further proposed a strategy of minimizing activation increments to find the important nodes, which can be used to limit the information propagation. Based on the rumor characteristics in social networks, Liu et al. [4] distinguished users into four compartments and further built a novel rumor spreading model. According to their theoretical results, one can select proper measures to control rumor propagation in the networks. Shrivastava et al. [5] built a system of differential equations to describe misinformation propagation among groups. They validated their model from theoretical and experimental aspects. Wang et al. [6] studied an energy propagation model of rumors on multiple social networks. They found effective rumor mitigation strategies by various model parameters on the networks. To clarify the relationship between misinformation and debunking information, Jiang et al. [7] proposed a novel RSD (rumorspreading-debunking) model. Their model obtained the scope, scale, and popularity about rumor spreading. Manouchehri et al. [8] proposed some techniques to generate required samples. They further found top-k nodes to minimize the impact of misinformation in social networks. Wang et al. [9] designed an optimal strategy of community seeds to reduce misinformation propagation and added it into their triggering model. Their method obtained better performance than all baseline models. Zareie and Sakellariou [10] summarized some methods about minimizing misinformation propagation. Therefore, misinformation 
propagation and control models can help researchers to design misinformation governance strategy in social networks.

Some scholars have integrated various influence factors into their methods to block misinformation propagation. Aswani et al. [11] investigated misinformation propagation factors by their experience in social media. They found that tweet sentiment, tweet polarity, network attributes, etc., influence misinformation propagation. Glenski et al. [12] investigated large amounts of news in social media. They found that spreading behaviors of trusted news source and suspicious news source are very different, such as diffusion rates, users' annual incomes, and educations. To identify potential misinformation propagators in social networks, Kar et al. [13] screened out eleven related factors from a large number of users and tweets. They further established a combined classification algorithm, which fused bioinspired algorithms with K-means method. Their findings presented that their proposed algorithm is able to identify propagators of the networks. Based on the sociological properties, psychological features, and persuasion theories, Chen et al. [14] studied the impact of persuasion strategies on the process of misinformation post-propagation in social networks. They found that pathos strategies are suitable persuasion strategies for misinformation propagation. Based on the topic of COVID-19 in Twitter, Shahi et al. [15] studied misinformation contents, authors, and diffusion. They found the three parts of influence misinformation propagation in social media. Considering that information propagation leads to the asynchronous process of initial opinion formation, Liu and Rong [16] introduced multiple impact factors including online communication, network topology, propagation rate, and repost rate, into their opinion dynamic model for public opinion misinformation. They found that compulsively deleting comments and timely exposing misinformation benefit the control of negative opinion. On the Internet of battlefield things (IoBT) system, Abuzainab and Saad [17] proposed a mean-field game model with multiclass agents. The experimental results showed that their model effectively suppressed misinformation propagation. Wang et al. [18] summarized the properties of misinformation propagation on published papers with health misinformation. They found that scholars adopted various methods including content analysis, co-citation analysis, and network analysis. Thus, a reasonable selection of parameters can help to establish good misinformation suppression models in social networks.

In recent, more and more researchers have studied the information propagation dynamics with evolutionary game methods. Xiao et al. [19] combined user multidimensional attributes, evolutionary games, and SIR epidemic model. They proposed a new propagation dynamic model with an evolutionary game. Based on their model, they analyzed the multisource information propagation and the complexity of user interaction behaviors. Li et al. [20] combined heterogeneous mean-field and evolutionary games and proposed a hot spot propagation model. They further analyzed the relationships between the users' desire to participate in hot spot and the infection rate of information propagation model. Wang et al. [21] proposed a tripartite evolutionary game model. They analyzed the equilibrium conditions of stakeholder's behavior strategies. They also studied management strategies and key intervention points of public opinion. Fei et al. [22] proposed an opinion dynamic model by evolutionary game theory. They analyzed the relationships of user behaviors, preferences, and ratings in this game model. To better understand information propagation scope and dynamic characteristics, Yang et al. [23] proposed an information propagation model with an evolutionary game. They further analyzed relationships between two pieces of competitive information. On the live streaming e-commerce networks, Lv et al. [24] proposed an information propagation game model with incentive mechanism. They further analyzed the relationships between rewards and live streaming information propagation based on the game model. Therefore, evolutionary games can better reveal the laws of information propagation in social networks.

In the field of misinformation spreading, Zhang et al. [25] investigated the propagation of conspiracy information and scientific information, respectively. In their experiments, they found that conspiracy information tends to propagate in a multigenerational branching process and science information tends to propagate in a breadth-first manner. To effectively constrain malicious actions in largescale MANETs, Wang et al. [26] proposed a trust cooperative stimulation model based on the evolutionary game methods. They further found an optimum strategy through their model. Xiao et al. [27] proposed an evolutionary game model to analyze the dynamics of rumor propagation. Their model considered anti-rumor information to find the reasons that users have spread rumors. To deal with the diversity and complexity of data in rumor communication, Xiao et al. [28] proposed a group behavior model for rumor and anti-rumor. Considering the conflict and symbiotic relationships between rumor and anti-rumor, they integrated userinfluenced rumor with anti-rumor based on the evolutionary game theory and representation learning methods. Askarizadeh et al. [29] proposed an evolutionary game model to reveal the relationships between rumor propagation and users' decision control. Askarizadeh et al. [30] also proposed a soft rumor control model to avoid rumor spreading. They further analyzed the relationships between rumor and antirumor spreaders based on the evolutionary game model. Consequently, evolutionary game models are useful to find misinformation (rumor) propagation and control rules.

Under multiple factors and circumstances, some scholars have analyzed their relationships based on the evolutionary game methods. Zhang et al. [31] introduced a reputation mechanism into evolutionary game theory and solved negative influences caused by malicious users. They further analyzed the relationships between current reputation and instant incentives based on the game model. In backscatter-assisted RF-powered cognitive networks, some secondary transmitters (STs) may choose different transmission services. Gao et al. [32] proposed an evolutionary game to analyze the relationship between the access point and service adaptation of the STs. To reveal the dynamic evolution of intervention policies, Alam et al. [33] combined 
some network topologies' social feedbacks, behavioral responses, and viral propagation into one framework. They analyzed the relationships among the game payoff, epidemic dynamics, and individual health statuses in social networks. To investigate the influences of node attitudes on information propagation, Huang et al. [34] used the evolutionary game method to build an information propagation model. They further analyzed relationships between positive and negative attitudes of nodes. Michael et al. [35] analyzed the trust game based on the previous work. They introduced "delays" and "memories" in the process of information propagation. They also found that information explained the trust and trustworthiness among users clearly and reasonably. Considering that "deceitful pricing for acquaintances" has received extensive public attention on e-commerce platforms, Wu et al. [36] proposed a tripartite evolutionary game model concerning consumers, government, and platforms. Their model provided reasonable selection schemes for the three participants. It concludes that the evolution analysis of information propagation need to be combined with the evolutionary game theory, network structures, individual features, etc., in social networks.

However, there are few results fusing misinformation propagation and tripartite evolutionary game methods. This study aims to establish a new tripartite evolutionary game model for misinformation propagation. Three players including network media, government, and netizen are considered in the tripartite evolutionary game model. The mutual influences of the players will be analyzed both theoretically and experimentally.

The rest of the study is arranged as follows. In Section 2, a tripartite evolutionary game model for misinformation propagation is described. The model construction, players' payoffs, and analysis of evolutionary stable strategies are presented in this section. In Section 3, some experiments under different parameters are made. Finally, the results are summarized; and some directions are proposed in the future.

\section{Tripartite Evolutionary Game Model for Misinformation Propagation}

\subsection{Description of the Tripartite Evolutionary Game Model} and the Players' Payoffs for Misinformation Propagation. In social networks, network media, government, and netizen play an important role in the process of misinformation propagation. The three participants reciprocally influence the networks, affecting the trends of misinformation propagation. The tripartite evolutionary game provides an effective way to analyze the impacts of participant behaviors on misinformation propagation. In the game, the three players are network media, government, and netizen, and their strategies are $\left(M_{1}, M_{2}\right),\left(G_{1}, G_{2}\right)$, and $\left(N_{1}, N_{2}\right)$. Each player only chooses a strategy without knowledge of the actual choices made by the other players. For the network media, $M_{1}$ and $M_{2}$ represent the strategies of "promoting misinformation propagation" (such as extensive report) and "blocking misinformation propagation" (such as selective report), respectively. For the government, $G_{1}$ and $G_{2}$ denote the strategies of "supervision" and "non-supervision," respectively. For the netizen, $N_{1}$ and $N_{2}$ represent the strategy of "spread" and "non-spread" media information. Therefore, the game strategies are $\left(M_{1}, G_{1}, N_{1}\right)$, $\left(M_{1}, G_{1}, N_{2}\right), \quad\left(M_{1}, G_{2}, N_{1}\right), \quad\left(M_{1}, G_{2}, N_{2}\right),\left(M_{2}, G_{1}, N_{1}\right)$, $\left(M_{2}, G_{1}, N_{2}\right),\left(M_{2}, G_{2}, N_{1}\right)$, and $\left(M_{2}, G_{2}, N_{2}\right)$, and their corresponding payoffs are denoted by $\left(\mathrm{PF}_{M 111}, \mathrm{PF}_{G 111}\right.$, $\left.\mathrm{PF}_{N 111}\right),\left(\mathrm{PF}_{\mathrm{M} 112}, \mathrm{PF}_{\mathrm{G} 112}, \mathrm{PF}_{N_{112}}\right),\left(\mathrm{PF}_{\mathrm{M}_{121}}, \mathrm{PF}_{\mathrm{G} 121}, \mathrm{PF}_{N_{121}}\right)$, $\left(\mathrm{PF}_{M 122}, \mathrm{PF}_{\mathrm{G}_{122}}, \mathrm{PF}_{\mathrm{N} 122}\right),\left(\mathrm{PF}_{M 211}, \mathrm{PF}_{\mathrm{G} 211}, \mathrm{PF}_{\mathrm{N} 211}\right),\left(\mathrm{PF}_{M 212}\right.$, $\left.\mathrm{PF}_{G 212}, \mathrm{PF}_{\mathrm{N} 212}\right), \quad\left(\mathrm{PF}_{M 221}, \mathrm{PF}_{G 221}, \mathrm{PF}_{N 221}\right)$, and $\left(\mathrm{PF}_{M 222}\right.$, $\left.\mathrm{PF}_{\mathrm{G} 222}, \mathrm{PF}_{\mathrm{N} 222}\right)$, respectively.

To quantitatively analyze the benefits of three players, which are correlated with misinformation propagation under each game strategy in more detail, the descriptions of parameters for the network media, government, and netizen are displayed in Tables 1-3, respectively.

According to the above terminologies and symbols, the payoff matrix of the tripartite evolutionary game is shown in Table 4, and the game tree of the tripartite evolutionary game, shown in Figure 1, is established to intuitively express the game among network media, government, and netizen. In the game tree, the circles in the front three rows represent the game players and the lines drawn from the players represent the strategies made by the players. The top circle represents that the network media select the information about some network misinformation and has two choices: promoting misinformation and blocking misinformation. The circles in the second row represent that the government selects the misinformation from the network media and may choose one of two strategies: supervision and non-supervision. In the third row, the circles represent that the netizen selects the misinformation from the network media and government and may choose to spread or not to spread the information. At the bottom of the game tree, the circles are terminal nodes of the game, which hold the benefits of three players to reach the corresponding terminals when they have chosen different strategies.

In the game process, it assumes that each player seeks to maximize its own benefit. According to the parameters of the network media, government, and netizen, the payoffs of the three players under different strategies are as follows:

$$
\begin{aligned}
\mathrm{PF}_{M 111} & =\mathrm{IM}_{0}+\mathrm{IM}_{1}-\mathrm{CM}_{1}-\mathrm{FM}_{1}, \\
\mathrm{PF}_{G 111} & =\mathrm{IG}_{0}+\mathrm{IG}_{1}-\mathrm{CG}, \\
\mathrm{PF}_{N 111} & =\mathrm{IN}_{0}-\mathrm{CN}-\mathrm{FN}_{1}, \\
\mathrm{PF}_{M 112} & =\mathrm{IM}_{0}+\mathrm{IM}_{1}-\mathrm{CM}_{1}-\mathrm{FM}_{1}-\mathrm{FM}_{3}, \\
\mathrm{PF}_{G 112} & =\mathrm{IG}_{0}+\mathrm{IG}_{1}-\mathrm{CG}+\mathrm{BG}_{1}, \\
\mathrm{PF}_{N 112} & =\mathrm{IN}_{0}+\mathrm{IN}_{3}-\mathrm{LN}, \\
\mathrm{PF}_{M 121} & =\mathrm{IM}_{0}+\mathrm{IM}_{1}-\mathrm{CM}_{1}+\mathrm{BM}_{1}, \\
\mathrm{PF}_{G 121} & =\mathrm{IG}_{0}+\mathrm{IG}_{2}-\mathrm{LG}_{1}, \\
\mathrm{PF}_{N 121} & =\mathrm{IN}_{0}+\mathrm{IN}_{1}-\mathrm{CN}_{1} \\
\mathrm{PF}_{M 122} & =\mathrm{IM}_{0}+\mathrm{IM}_{1}-\mathrm{CM}_{1}, \\
\mathrm{PF}_{G 122} & =\mathrm{IG}_{0}+\mathrm{IG}_{2}-\mathrm{LG}_{1}-\mathrm{FG}_{1},
\end{aligned}
$$


TABle 1: Parameters of the network media.

\begin{tabular}{|c|c|}
\hline Parameters & Descriptions of the parameters for the network media \\
\hline $\mathrm{IM}_{0}$ & The initial income from the advertisements \\
\hline $\mathrm{IM}_{1}$ & $\begin{array}{l}\text { The income from the increasing advertisements, click rate, new netizen, popularity, etc., of the network media, when network } \\
\text { media choose } M_{1}\end{array}$ \\
\hline $\mathrm{IM}_{2}$ & The profit from the government attention, $\mathrm{n}$ \\
\hline $\mathrm{CM}_{1}$ & The cost from manpower, material resou \\
\hline $\mathrm{CM}_{2}$ & The cost from manpower, material resou. \\
\hline $\mathrm{BM}_{1}$ & e $M_{1}, G_{2}$, and $N_{1}$, respectively \\
\hline $\mathrm{BM}_{2}$ & hoose $M_{2}, G_{2}$, and $N_{1}$, respectively \\
\hline LM & The loss from the decreasing advertisements, click rate \\
\hline $\mathrm{FM}_{1}$ & The fine from the oovernment $c$ \\
\hline $\mathrm{FM}_{2}$ & $M_{2}\left(\mathrm{FM}_{2}<\mathrm{FM}_{1}\right)$ \\
\hline $\mathrm{FM}_{3}$ & $\begin{array}{l}\text { The fine from the netizen who no longer trusts or follows the network media, when the network media, government, and } \\
\text { netizen choose } M_{1}, G_{1} \text {, and } N_{2} \text {, respectively }\end{array}$ \\
\hline $\mathrm{FM}_{4}$ & The fine from the netizen who no longer \\
\hline
\end{tabular}

TABLE 2: Parameters of the government.

\begin{tabular}{|c|c|}
\hline Parameters & Descriptions of the parameters for the government \\
\hline $\mathrm{IG}_{0}$ & The initial income from the power of government image, credibility, etc. \\
\hline $\mathrm{IG}_{1}$ & $\begin{array}{c}\text { The profit from the increasing power of government image, credibility, etc., and the security and stability of cyberspace, when } \\
\text { the government chooses } G_{1}\end{array}$ \\
\hline $\mathrm{IG}_{2}$ & $\begin{array}{l}\text { The profit from the increasing tax of the network media, increasing public service advertisements, etc., when the government } \\
\text { chooses } G_{2}\left(\mathrm{IG}_{2}<\mathrm{IG}_{1}<\mathrm{IG}_{0}\right)\end{array}$ \\
\hline CG & The cost from manpower, material resources, etc., when the government chooses $G_{1}$ \\
\hline $\mathrm{LG}_{1}$ & $\begin{array}{l}\text { The loss from the damage of the government image power, credibility, even unstable, and disharmonious cyberspace, when } \\
\text { the network media choose } M_{1} \text { and the government chooses } G_{2}\end{array}$ \\
\hline $\mathrm{LG}_{2}$ & $\begin{array}{l}\text { The loss from the damage of the government image power, credibility, even unstable, and disharmonious cyberspace, when } \\
\text { the network media choose } M_{2} \text { and the government chooses } G_{2}\left(\mathrm{LG}_{2}<\mathrm{LG}_{1}\right)\end{array}$ \\
\hline $\mathrm{BG}_{1}$ & $\begin{array}{l}\text { The bonus from the netizen who trusts the government and chooses non-spread media misinformation, when the network } \\
\text { media choose } M_{1} \text { and the government chooses } G_{1}\end{array}$ \\
\hline $\mathrm{BG}_{2}$ & $\begin{array}{l}\text { The bonus from the netizen who trusts the government and chooses non-spread media misinformation, when the network } \\
\text { media choose } M_{2} \text { and the government chooses } G_{1}\left(\mathrm{BG}_{2}<\mathrm{BG}_{1}\right)\end{array}$ \\
\hline $\mathrm{FG}_{1}$ & $\begin{array}{l}\text { The fine from the netizen who distrusts the government and chooses non-spread media misinformation, when the network } \\
\text { media choose } M_{1} \text { and the government chooses } G_{2}\end{array}$ \\
\hline $\mathrm{FG}_{2}$ & $\begin{array}{l}\text { The fine from the netizen who distrusts the government and chooses non-spread media misinformation, when the network } \\
\text { media choose } M_{2} \text { and the government chooses } G_{2}\left(\mathrm{FG}_{2}<\mathrm{FG}_{1}\right)\end{array}$ \\
\hline
\end{tabular}

TABLE 3: Parameters of the netizen.

Parameters Descriptions of the parameters for the netizen

$\mathrm{IN}_{0} \quad$ The initial income from the netizen who have increasing attention, influence, etc.

$\mathrm{IN}_{1} \quad$ The profit from the increasing attention, influence, etc., when the network media, government, and netizen choose $M_{1}, G_{2}$, and $N_{1}$, respectively

$\mathrm{N}_{2}$ The profit from the increasing attention, influence, etc., when the network media, government, and netizen choose $M_{2}, G_{2}$, and $N_{1}$, respectively

$\mathrm{IN}_{3} \quad$ The profit from stable and harmonious cyberspace, etc., when the netizen chooses $N_{2}$

$\mathrm{CN}$ The cost from manpower, material resources, time, etc., when the netizen collects and organizes misinformation, and chooses $N_{1}$

LN The loss from decreasing attention, followers, etc., when the netizen chooses $N_{2}$
FN $_{1} \quad$ The fine from the government when the network media, government, and netizen choose $M_{1}, G_{1}$, a

$\mathrm{FN}_{1} \quad$ The fine from the government when the network media, government, and netizen choose $M_{1}, G_{1}$, and $N_{1}$, respectively

$\mathrm{FN}_{2} \quad$ The fine from the government when the network media, government, and netizen choose $M_{2}, G_{1}$, and $N_{1}$, respectively.

TABLE 4: Payoff matrix of the tripartite evolutionary game.

\begin{tabular}{lr}
\hline Game strategies & Incomes \\
\hline$\left(M_{1}, G_{1}, N_{1}\right)$ & $\left(\mathrm{PF}_{M 111}, \mathrm{PF}_{G 111}, \mathrm{PF}_{N 111}\right)$ \\
$\left(M_{1}, G_{1}, N_{2}\right)$ & $\left(\mathrm{PF}_{M 112}, \mathrm{PF}_{G 112}, \mathrm{PF}_{N 112}\right)$ \\
$\left(M_{1}, G_{2}, N_{1}\right)$ & $\left(\mathrm{PF}_{M 121}, \mathrm{PF}_{G 121}, \mathrm{PF}_{N 121}\right)$ \\
$\left(M_{1}, G_{2}, N_{2}\right)$ & $\left(\mathrm{PF}_{M 122}, \mathrm{PF}_{G 122}, \mathrm{PF}_{N 122}\right)$ \\
$\left(M_{2}, G_{1}, N_{1}\right)$ & $\left(\mathrm{PF}_{M 211}, \mathrm{PF}_{G 211}, \mathrm{PF}_{N 211}\right)$ \\
$\left(M_{2}, G_{1}, N_{2}\right)$ & $\left(\mathrm{PF}_{M 212}, \mathrm{PF}_{G 212}, \mathrm{PF}_{N 212}\right)$ \\
$\left(M_{2}, G_{2}, N_{1}\right)$ & $\left(\mathrm{PF}_{M 221}, \mathrm{PF}_{G 221}, \mathrm{PF}_{N 221}\right)$ \\
$\left(M_{2}, G_{2}, N_{2}\right)$ & $\left(\mathrm{PF}_{M 222}, \mathrm{PF}_{G 222}, \mathrm{PF}_{N 222}\right)$ \\
\hline
\end{tabular}




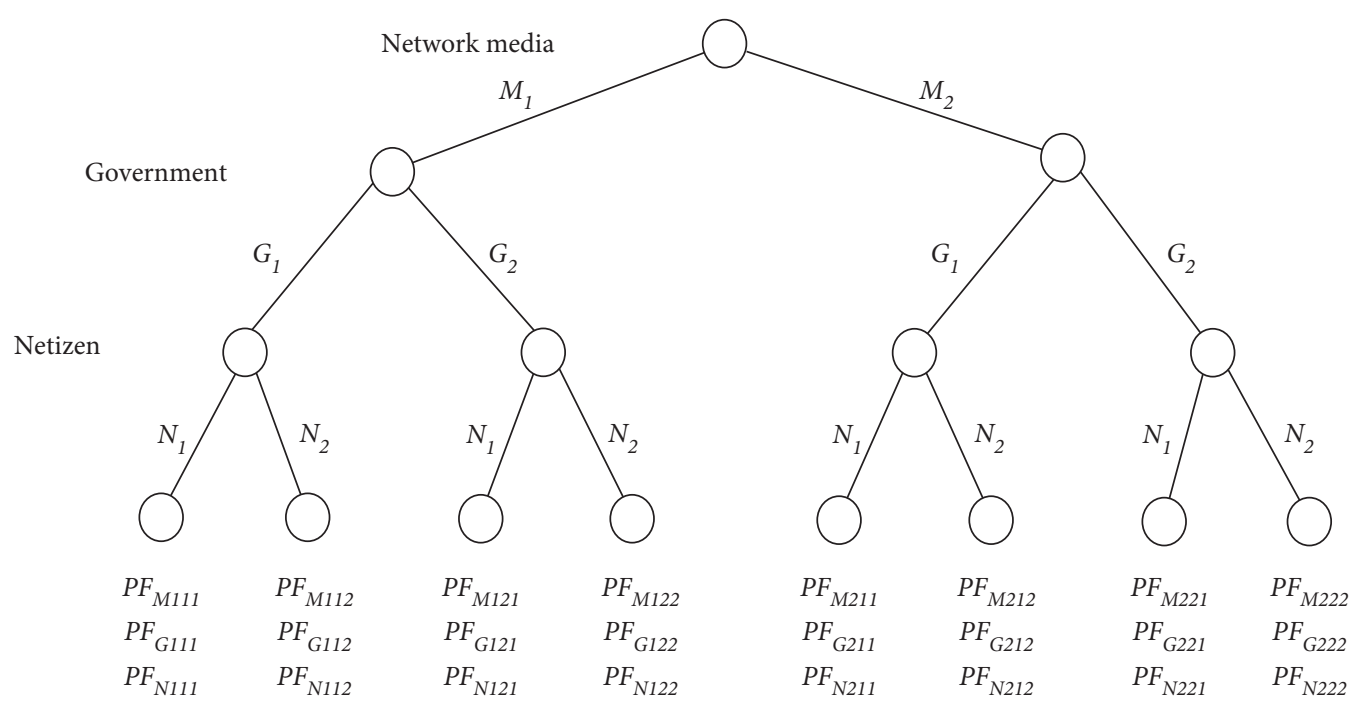

Figure 1: Game tree of the tripartite evolutionary game.

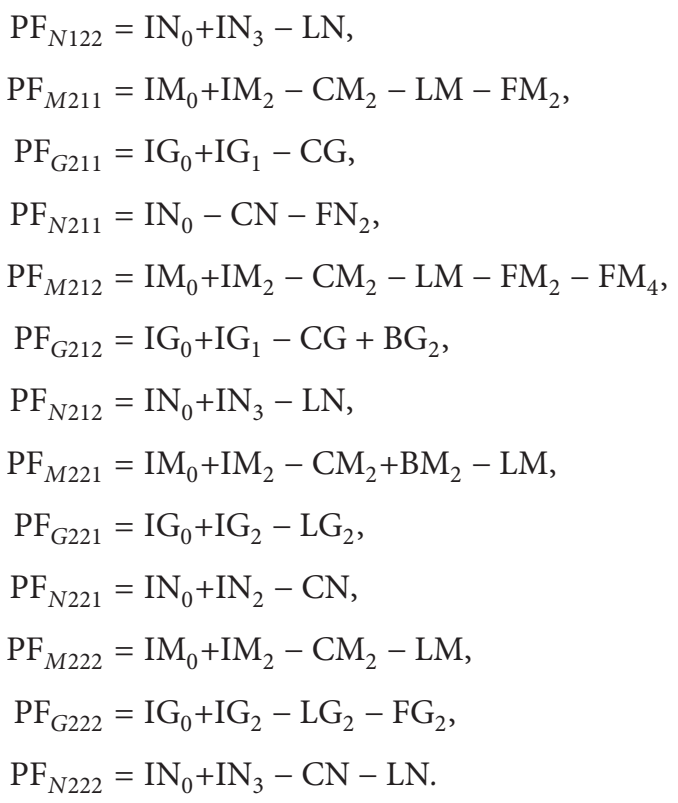

Let $x, y$, and $z$ be the function of time $t$. If the network media, government, and netizen, respectively, choose the strategies $M_{1}, G_{1}$, and $N_{1}$, then their probabilities are correspondingly $x, y$, and $z$; if the network media, government, and netizen, respectively, choose the strategies $M_{2}$, $G_{2}$, and $N_{2}$, then their probabilities are correspondingly $1-x, 1-y$, and $1-z$. Next, the expected payoffs of the network media, government, and netizen will be analyzed as follows.

If the network media choose the strategy $M_{1}$, the expected payoff of the network media in this case, denoted by $\mathrm{EM}_{1}$, is as follows:

$$
\begin{aligned}
\mathrm{EM}_{1}= & y z \mathrm{PF}_{M 111}+y(1-z) \mathrm{PF}_{M 112}+(1-y) z \mathrm{PF}_{M 121}+(1-y)(1-z) \mathrm{PF}_{M 122} \\
= & y z\left(\mathrm{IM}_{0}+\mathrm{IM}_{1}-\mathrm{CM}_{1}-\mathrm{FM}_{1}\right)+y(1-z)\left(\mathrm{IM}_{0}+\mathrm{IM}_{1}-\mathrm{CM}_{1}-\mathrm{FM}_{1}-\mathrm{FM}_{3}\right) \\
& +(1-y) z\left(\mathrm{IM}_{0}+\mathrm{IM}_{1}-\mathrm{CM}_{1}+\mathrm{BM}_{1}\right)+(1-y)(1-z)\left(\mathrm{IM}_{0}+\mathrm{IM}_{1}-\mathrm{CM}_{1}\right), \\
= & y z\left(\mathrm{FM}_{3}-\mathrm{BM}_{1}\right)-y\left(\mathrm{FM}_{1}+\mathrm{FM}_{3}\right)+z \mathrm{BM}_{1}+\mathrm{IM}_{0}+\mathrm{IM}_{1}-\mathrm{CM}_{1} .
\end{aligned}
$$

If the network media choose the strategy $M_{2}$, the expected payoff of the network media in this case, denoted by $\mathrm{EM}_{2}$, is as follows: 


$$
\begin{aligned}
\mathrm{EM}_{2}= & y z \mathrm{PF}_{M 211}+y(1-z) \mathrm{PF}_{M 212}+(1-y) z \mathrm{PF}_{M 221}+(1-y)(1-z) \mathrm{PF}_{M 222} \\
= & y z\left(\mathrm{IM}_{0}+\mathrm{IM}_{2}-\mathrm{CM}_{2}-\mathrm{LM}-\mathrm{FM}_{2}\right)+y(1-z)\left(\mathrm{IM}_{0}+\mathrm{IM}_{2}-\mathrm{CM}_{2}-\mathrm{LM}-\mathrm{FM}_{2}-\mathrm{FM}_{4}\right) \\
& +(1-y) z\left(\mathrm{IM}_{0}+\mathrm{IM}_{2}-\mathrm{CM}_{2}+\mathrm{BM}_{2}-\mathrm{LM}\right)+(1-y)(1-z)\left(\mathrm{IM}_{0}+\mathrm{IM}_{2}-\mathrm{CM}_{2}-\mathrm{LM}\right) \\
= & y z\left(\mathrm{FM}_{4}-\mathrm{BM}_{2}\right)-y\left(\mathrm{FM}_{2}+\mathrm{FM}_{4}\right)+z \mathrm{BM}_{2}+\mathrm{IM}_{0}+\mathrm{IM}_{2}-\mathrm{CM}_{2}-\mathrm{LM} .
\end{aligned}
$$

For the mixed strategy of the network media, the expected payoff of the network media, denoted by EM, is as follows:

$$
\begin{aligned}
\mathrm{EM}= & x \mathrm{EM}_{1}+(1-x) \mathrm{EM}_{2} \\
= & x y z \mathrm{PF}_{M 111}+x y(1-z) \mathrm{PF}_{M 112}+x(1-y) z \mathrm{PF}_{M 121}+x(1-y)(1-z) \mathrm{PF}_{M 122} \\
& +(1-x) y z \mathrm{PF}_{M 211}+(1-x) y(1-y) \mathrm{PF}_{M 212}+(1-x)(1-y) z \mathrm{PF}_{M 221}+(1-x)(1-y)(1-z) \mathrm{PF}_{M 222} \\
= & x y z\left(\mathrm{FM}_{3}-\mathrm{FM}_{4}-\mathrm{BM}_{1}+\mathrm{BM}_{2}\right)-x y\left(\mathrm{FM}_{1}-\mathrm{FM}_{2}+\mathrm{FM}_{3}-\mathrm{FM}_{4}\right)+x z\left(\mathrm{BM}_{1}-\mathrm{BM}_{2}\right)+y z\left(\mathrm{FM}_{4}-\mathrm{BM}_{2}\right) \\
& +x\left(\mathrm{IM}_{1}-\mathrm{IM}_{2}-\mathrm{CM}_{1}+\mathrm{CM}_{2}+\mathrm{LM}\right)-y\left(\mathrm{FM}_{2}+\mathrm{FM}_{4}\right)+z \mathrm{BM}_{2}+\mathrm{IM}_{0}+\mathrm{IM}_{2}-\mathrm{CM}_{2}-\mathrm{LM}
\end{aligned}
$$

If the government chooses the strategy $G_{1}$, the expected payoff of the network media in this case, denoted by $\mathrm{EG}_{1}$, is as follows:

$$
\begin{aligned}
\mathrm{EG}_{1}= & x z \mathrm{PF}_{G 111}+x(1-z) \mathrm{PF}_{G 112}+(1-x) z \mathrm{PF}_{\mathrm{G} 211}+(1-x)(1-z) \mathrm{PF}_{\mathrm{G} 212} \\
= & x z\left(\mathrm{IG}_{0}+\mathrm{IG}_{1}-\mathrm{CG}\right)+x(1-z)\left(\mathrm{IG}_{0}+\mathrm{IG}_{1}-\mathrm{CG}+\mathrm{BG}_{1}\right)+(1-x) z\left(\mathrm{IG}_{0}+\mathrm{IG}_{1}-\mathrm{CG}\right) \\
& +(1-x)(1-z)\left(\mathrm{IG}_{0}+\mathrm{IG}_{1}-\mathrm{CG}+\mathrm{BG}_{2}\right) \\
= & -x z\left(\mathrm{BG}_{1}-\mathrm{BG}_{2}\right)+x\left(\mathrm{BG}_{1}-\mathrm{BG}_{2}\right)-z\left(\mathrm{IG}_{0}+\mathrm{IG}_{1}-\mathrm{CG}+\mathrm{BG}_{2}\right)+\left(2 \mathrm{IG}_{0}+2 \mathrm{IG}_{1}-2 \mathrm{CG}+\mathrm{BG}_{2}\right) .
\end{aligned}
$$

If the government chooses the strategy $G_{2}$, the expected payoff of the government in this case, denoted by $\mathrm{EG}_{2}$, is as follows:

$$
\begin{aligned}
\mathrm{EG}_{2}= & x z \mathrm{PF}_{G 121}+x(1-z) \mathrm{PF}_{G 122}+(1-x) z \mathrm{PF}_{G 221}+(1-x)(1-z) \mathrm{PF}_{G 222} \\
= & x z\left(\mathrm{IG}_{0}+\mathrm{IG}_{2}-\mathrm{LG}_{1}\right)+x(1-z)\left(\mathrm{IG}_{0}+\mathrm{IG}_{2}-\mathrm{LG}_{1}-\mathrm{FG}_{1}\right)+(1-x) z\left(\mathrm{IG}_{0}+\mathrm{IG}_{2}-\mathrm{LG}_{2}\right) \\
& +(1-x)(1-z)\left(\mathrm{IG}_{0}+\mathrm{IG}_{2}-\mathrm{LG}_{2}-\mathrm{FG}_{2}\right) \\
= & x z\left(\mathrm{FG}_{1}-\mathrm{FG}_{2}\right)-x\left(\mathrm{FG}_{1}-\mathrm{FG}_{2}+\mathrm{LG}_{1}-\mathrm{LG}_{2}\right)+z \mathrm{FG}_{2}+\mathrm{IG}_{0}+\mathrm{IG}_{2}-\mathrm{LG}_{2}-\mathrm{FG}_{2} .
\end{aligned}
$$

For the mixed strategy of the government, the expected payoff of the government, denoted by EG, is as follows: 


$$
\begin{aligned}
\mathrm{EG}= & y \mathrm{EG}_{1}+(1-y) \mathrm{EG}_{2}=x y z \mathrm{PF}_{G 111}+x y(1-z) \mathrm{PF}_{G 112}+(1-x) y z \mathrm{PF}_{G 211}+(1-x) y(1-z) \mathrm{PF}_{G 212} \\
& +x(1-y) z \mathrm{PF}_{G 121}+x(1-y)(1-z) \mathrm{PF}_{G 122}+(1-x)(1-y) z \mathrm{PF}_{G 221}+(1-x)(1-y)(1-z) \mathrm{PF}_{G 222} \\
= & -x y z\left(\mathrm{BG}_{1}-\mathrm{BG}_{2}+\mathrm{FG}_{1}-\mathrm{FG}_{2}\right)+x y\left(\mathrm{BG}_{1}-\mathrm{BG}_{2}+\mathrm{FG}_{1}-\mathrm{FG}_{2}+\mathrm{LG}_{1}-\mathrm{LG}_{2}\right)+x z\left(\mathrm{FG}_{1}-\mathrm{FG}_{2}\right) \\
& -y z\left(\mathrm{IG}_{0}+\mathrm{IG}_{1}+\mathrm{IG}_{2}-\mathrm{CG}+\mathrm{FG}_{2}\right)-x\left(\mathrm{FG}_{1}-\mathrm{FG}_{2}+\mathrm{LG}_{1}-\mathrm{LG}_{2}\right) \\
& +y\left(\mathrm{IG}_{0}+2 \mathrm{IG}_{1}-\mathrm{IG}_{2}+\mathrm{BG}_{2}-2 \mathrm{CG}+\mathrm{LG}_{2}+\mathrm{FG}_{2}\right)+z \mathrm{FG}_{2}+\mathrm{IG}_{0}+\mathrm{IG}_{2}-\mathrm{LG}_{2}-\mathrm{FG}_{2} .
\end{aligned}
$$

If the netizen chooses the strategy $N_{1}$, the expected payoff of the netizen in this case, denoted by $\mathrm{EN}_{1}$, is as follows:

$$
\begin{aligned}
\mathrm{EN}_{1} & =x y \mathrm{PF}_{N 111}+x(1-y) \mathrm{PF}_{N 121}+(1-x) y \mathrm{PF}_{N 211}+(1-x)(1-y) \mathrm{PF}_{N 221} \\
& =x y\left(\mathrm{IN}_{0}-\mathrm{CN}-\mathrm{FN}_{1}\right)+x(1-y)\left(\mathrm{IN}_{0}+\mathrm{IN}_{1}-\mathrm{CN}\right)+(1-x) y\left(\mathrm{IN}_{0}-\mathrm{CN}-\mathrm{FN}_{2}\right)+(1-x)(1-y)\left(\mathrm{IN}_{0}+\mathrm{IN}_{2}-\mathrm{CN}\right) \\
& =-x y\left(\mathrm{IN}_{1}-\mathrm{IN}_{2}+\mathrm{FN}_{1}\right)+x\left(\mathrm{IN}_{1}-\mathrm{IN}_{2}\right)-y\left(\mathrm{IN}_{2}+\mathrm{FN}_{2}\right)+\mathrm{IN}_{0}+\mathrm{IN}_{2}-\mathrm{CN}
\end{aligned}
$$

If the netizen chooses the strategy $N_{2}$, the expected payoff of the netizen in this case, denoted by $\mathrm{EN}_{2}$, is as follows:

$$
\begin{aligned}
\mathrm{EN}_{2}= & x y \mathrm{PF}_{N 112}+x(1-y) \mathrm{PF}_{N 122}+(1-x) y \mathrm{PF}_{N 212}+(1-x)(1-y) \mathrm{PF}_{N 222} \\
= & x y\left(\mathrm{IN}_{0}+\mathrm{IN}_{3}-\mathrm{LN}\right)+x(1-y)\left(\mathrm{IN}_{0}+\mathrm{IN}_{3}-\mathrm{LN}\right)+(1-x) y\left(\mathrm{IN}_{0}+\mathrm{IN}_{3}-\mathrm{LN}\right) \\
& +(1-x)(1-y)\left(\mathrm{IN}_{0}+\mathrm{IN}_{3}-\mathrm{CN}-\mathrm{LN}\right) \\
= & -x y \mathrm{CN}+x \mathrm{CN}+y \mathrm{CN}+\mathrm{IN}_{0}+\mathrm{IN}_{3}-\mathrm{CN}-\mathrm{LN} .
\end{aligned}
$$

For the mixed strategy of the netizen, the expected payoff of the netizen, denoted by $\mathrm{EN}$, is as follows:

$$
\begin{aligned}
\mathrm{EN}= & z \mathrm{EN}_{1}+(1-z) \mathrm{EN}_{2} \\
= & x y z \mathrm{PF}_{N 111}+x(1-y) z \mathrm{PF}_{N 121}+(1-x) y z \mathrm{PF}_{N 211}+(1-x)(1-y) z \mathrm{PF}_{N 221}+x y(1-z) \mathrm{PF}_{N 112} \\
& +x(1-y)(1-z) \mathrm{PF}_{N 122}+(1-x) y(1-z) \mathrm{PF}_{N 212}+(1-x)(1-y)(1-z) \mathrm{PF}_{N 222} \\
= & -x y z\left(\mathrm{IN}_{1}-\mathrm{IN}_{2}+\mathrm{FN}_{1}-\mathrm{CN}\right)-x y \mathrm{CN}+x z\left(\mathrm{IN}_{1}-\mathrm{IN}_{2}-\mathrm{CN}\right)-y z\left(\mathrm{IN}_{2}+\mathrm{FN}_{2}+\mathrm{CN}\right) \\
& +x \mathrm{CN}+y \mathrm{CN}+z\left(\mathrm{IN}_{2}-\mathrm{IN}_{3}+\mathrm{LN}\right)+\mathrm{IN}_{0}+\mathrm{IN}_{3}-\mathrm{CN}-\mathrm{LN} .
\end{aligned}
$$

2.2. Theoretical Analysis of Evolutionary Stable Strategies. To ensure the harmonious and stable development of the network society, to promote the sustainable development of the network media, and to protect the legitimate rights of the netizen, the network media, government, and netizen should fulfill their responsibilities to reduce the probabilities of propagating misinformation. By the expected payoffs of the network media, government, and netizen, their evolutionary replication dynamic equations are as follows: 


$$
\begin{aligned}
& f(x)=\frac{\mathrm{d} x}{\mathrm{~d} t}=x\left(\mathrm{EM}_{1}-\mathrm{EM}\right)=x(1-x)\left(\mathrm{EM}_{1}-\mathrm{EM}_{2}\right) \\
& =x(1-x)\left[y z \mathrm{PF}_{M 111}+y(1-z) \mathrm{PF}_{M 112}+(1-y) z \mathrm{PF}_{M 121}+(1-y)(1-z) \mathrm{PF}_{M 122}-y z \mathrm{PF}_{M 211}\right. \\
& \left.-y(1-z) \mathrm{PF}_{M 212}-(1-y) z \mathrm{PF}_{M 221}-(1-y)(1-z) \mathrm{PF}_{M 222}\right] \\
& =x(1-x)\left[y z\left(\mathrm{FM}_{3}-\mathrm{FM}_{4}-\mathrm{BM}_{1}+\mathrm{BM}_{2}\right)-y\left(\mathrm{FM}_{1}-\mathrm{FM}_{2}+\mathrm{FM}_{3}-\mathrm{FM}_{4}\right)\right)+z\left(\mathrm{BM}_{1}-\mathrm{BM}_{2}\right) \\
& \left.+\mathrm{IM}_{1}-\mathrm{IM}_{2}-\mathrm{CM}_{1}+\mathrm{CM}_{2}+\mathrm{LM}\right] \\
& g(y)=\frac{\mathrm{d} y}{\mathrm{~d} t}=y\left(\mathrm{EG}_{1}-\mathrm{EG}\right)=y(1-y)\left(\mathrm{EG}_{1}-\mathrm{EG}_{2}\right) \\
& =y(1-y)\left[x z \mathrm{PF}_{G 111}+x(1-z) \mathrm{PF}_{G 112}+(1-x) z \mathrm{PF}_{G 211}+(1-x)(1-z) \mathrm{PF}_{G 212}\right. \\
& \left.-x z \mathrm{PF}_{G 121}-x(1-z) \mathrm{PF}_{G 122}-(1-x) z \mathrm{PF}_{G 221}-(1-x)(1-z) \mathrm{PF}_{G 222}\right] \\
& =y(1-y)\left[-x z\left(\mathrm{BG}_{1}-\mathrm{BG}_{2}+\mathrm{FG}_{1}-\mathrm{FG}_{2}\right)+x\left(\mathrm{BG}_{1}-\mathrm{BG}_{2}+\mathrm{FG}_{1}-\mathrm{FG}_{2}+\mathrm{LG}_{1}-\mathrm{LG}_{2}\right)\right. \\
& \left.-z\left(\mathrm{IG}_{0}+\mathrm{IG}_{1}-\mathrm{CG}+\mathrm{BG}_{2}+\mathrm{FG}_{2}\right)+\left(\mathrm{IG}_{0}+2 \mathrm{IG}_{1}-\mathrm{IG}_{2}-2 \mathrm{CG}+\mathrm{BG}_{2}+\mathrm{LG}_{2}+\mathrm{FG}_{2}\right)\right] \text {, } \\
& h(z)=\frac{\mathrm{d} z}{\mathrm{~d} t}=z\left(\mathrm{EN}_{1}-\mathrm{EN}\right)=z(1-z)\left(\mathrm{EN}_{1}-\mathrm{EN}_{2}\right) \\
& =z(1-z)\left[x y \mathrm{PF}_{N 111}+x(1-y) \mathrm{PF}_{N 121}+(1-x) y \mathrm{PF}_{N 211}+(1-x)(1-y) \mathrm{PF}_{N 221}-x y \mathrm{PF}_{N 112}\right. \\
& \left.-x(1-y) \mathrm{PF}_{N 122}-(1-x) y \mathrm{PF}_{N 212}-(1-x)(1-y) \mathrm{PF}_{N 222}\right] \\
& =z(1-z)\left[-x y\left(\mathrm{IN}_{1}-\mathrm{IN}_{2}+\mathrm{FN}_{1}+\mathrm{CN}\right)+x\left(\mathrm{IN}_{1}-\mathrm{IN}_{2}-\mathrm{CN}\right)-y\left(\mathrm{IN}_{2}+\mathrm{FN}_{2}+\mathrm{CN}\right)+\mathrm{IN}_{2}-\mathrm{IN}_{3}+\mathrm{LN}\right] \text {. }
\end{aligned}
$$

Then, the tripartite evolutionary stabilities of the replication dynamic equations (11)-(13) can be analyzed by the following Jacobian matrix:

$$
J_{(x, y, z)}=\left[\begin{array}{lll}
f_{x} & f_{y} & f_{z} \\
g_{x} & g_{y} & g_{z} \\
h_{x} & h_{y} & h_{z}
\end{array}\right],
$$

where the elements of $J_{(x, y, z)}$ are as follows.

$$
\begin{aligned}
f_{x}= & (1-2 x)\left[y z \mathrm{PF}_{M 111}+y(1-z) \mathrm{PF}_{M 112}+(1-y) z \mathrm{PF}_{M 121}+(1-y)(1-z) \mathrm{PF}_{M 122}-y z \mathrm{PF}_{M 211}\right. \\
& \left.-y(1-z) \mathrm{PF}_{M 212}-(1-y) z \mathrm{PF}_{M 221}-(1-y)(1-z) \mathrm{PF}_{M 222}\right] \\
= & (1-2 x)\left[y z\left(\mathrm{FM}_{3}-\mathrm{FM}_{4}-\mathrm{BM}_{1}+\mathrm{BM}_{2}\right)-y\left(\mathrm{FM}_{1}-\mathrm{FM}_{2}+\mathrm{FM}_{3}-\mathrm{FM}_{4}\right)+z\left(\mathrm{BM}_{1}-\mathrm{BM}_{2}\right)+\mathrm{IM}_{1}\right. \\
& \left.-\mathrm{IM}_{2}-\mathrm{CM}_{1}+\mathrm{CM}_{2}+\mathrm{LM}\right] \\
f_{y}= & x(1-x)\left[z \mathrm{PF}_{M 111}+(1-z) \mathrm{PF}_{M 112}-z \mathrm{PF}_{M 121}-(1-z) \mathrm{PF}_{M 122}-z \mathrm{PF}_{M 211}-(1-z) \mathrm{PF}_{M 212}+z \mathrm{PF}_{M 221}+(1-z) \mathrm{PF}_{M 222}\right] \\
= & x(1-x)\left[z\left(\mathrm{FM}_{3}-\mathrm{FM}_{4}-\mathrm{BM}_{1}+\mathrm{BM}_{2}\right)-\left(\mathrm{FM}_{1}-\mathrm{FM}_{2}+\mathrm{FM}_{3}-\mathrm{FM}_{4}\right)\right] \\
f_{z}= & x(1-x)\left[y \mathrm{PF}_{M 111}-y \mathrm{PF}_{M 112}+(1-y) \mathrm{PF}_{M 121}-(1-y) \mathrm{PF}_{M 122}-y \mathrm{PF}_{M 211}+y \mathrm{PF}_{M 212}-(1-y) \mathrm{PF}_{M 221}+(1-y) \mathrm{PF}_{M 222}\right] \\
= & x(1-x)\left[y\left(\mathrm{FM}_{3}-\mathrm{FM}_{4}-\mathrm{BM}_{1}+\mathrm{BM}_{2}\right)+\left(\mathrm{BM}_{1}-\mathrm{BM}_{2}\right)\right] \\
g_{x}= & y(1-y)\left[z \mathrm{PF}_{G 111}+(1-z) \mathrm{PF}_{G 112}-z \mathrm{PF}_{\mathrm{G} 211}-(1-z) \mathrm{PF}_{G 212}-z \mathrm{PF}_{G 121}-(1-z) \mathrm{PF}_{G 122}+z \mathrm{PF}_{G 221}+(1-z) \mathrm{PF}_{G 222}\right] \\
= & y(1-y)\left[-z\left(\mathrm{BG}_{1}-\mathrm{BG}_{2}+\mathrm{FG}_{1}-\mathrm{FG}_{2}\right)+\left(\mathrm{BG}_{1}-\mathrm{BG}_{2}+\mathrm{FG}_{1}-\mathrm{FG}_{2}+\mathrm{LG}_{1}-\mathrm{LG}_{2}\right),\right. \\
g_{y}= & (1-2 y)\left[x z \mathrm{PF}_{G 111}+x(1-z) \mathrm{PF}_{G 112}+(1-x) z \mathrm{PF}_{G 211}+(1-x)(1-z) \mathrm{PF}_{G_{212}}-x z \mathrm{PF}_{G 121}\right. \\
& \left.-x(1-z) \mathrm{PF}_{G 122}-(1-x) z \mathrm{PF}_{G_{221}}-(1-x)(1-z) \mathrm{PF}_{G 222}\right] \\
= & (1-2 y)\left[-x z\left(\mathrm{BG}_{1}-\mathrm{BG}_{2}+\mathrm{FG}_{1}-\mathrm{FG}_{2}\right)+x\left(\mathrm{BG}_{1}-\mathrm{BG}_{2}+\mathrm{FG}_{1}-\mathrm{FG}_{2}+\mathrm{LG}_{1}-\mathrm{LG}_{2}\right)\right. \\
& \left.-z\left(\mathrm{IG}_{0}+\mathrm{IG}_{1}-\mathrm{CG}_{+} \mathrm{BG}_{2}+\mathrm{FG}_{2}\right)+\left(\mathrm{IG}_{0}+2 \mathrm{IG}_{1}-\mathrm{IG}_{2}-2 \mathrm{CG}_{+} \mathrm{BG}_{2}+\mathrm{LG}_{2}+\mathrm{FG}_{2}\right)\right] \\
g_{z}= & y(1-y)\left[x \mathrm{PF}_{G 111}-x \mathrm{PF}_{G 112}+(1-x) \mathrm{PF}_{G 211}-(1-x) \mathrm{PF}_{G 212}-x \mathrm{PF}_{G 121}+x \mathrm{PF}_{G 122}-(1-x) \mathrm{PF}_{G 221}+(1-x) \mathrm{PF}_{G 222}\right]
\end{aligned}
$$




$$
\begin{aligned}
= & y(1-y)\left[-x\left(\mathrm{BG}_{1}-\mathrm{BG}_{2}+\mathrm{FG}_{1}-\mathrm{FG}_{2}\right)-\left(\mathrm{IG}_{0}+\mathrm{IG}_{1}-\mathrm{CG}+\mathrm{BG}_{2}+\mathrm{FG}_{2}\right),\right. \\
h_{x}= & z(1-z)\left[y \mathrm{PF}_{N 111}+(1-y) \mathrm{PF}_{N 121}-y \mathrm{PF}_{N 211}-(1-y) \mathrm{PF}_{N 221}-y \mathrm{PF}_{N 112}-(1-y) \mathrm{PF}_{N 122}+y \mathrm{PF}_{N 212}+(1-y) \mathrm{PF}_{N 222}\right] \\
= & z(1-z)\left[-y\left(\mathrm{IN}_{1}-\mathrm{IN}_{2}+\mathrm{FN}_{1}+\mathrm{CN}\right)+\left(\mathrm{IN}_{1}-\mathrm{IN}_{2}-\mathrm{CN}\right)-y\left(\mathrm{IN}_{2}+\mathrm{FN}_{2}+\mathrm{CN}\right)\right], \\
h_{y}= & z(1-z)\left[x \mathrm{PF}_{N 111}-x \mathrm{PF}_{N 121}+(1-x) \mathrm{PF}_{N 211}-(1-x) \mathrm{PF}_{N 221}-x \mathrm{PF}_{N 112}+x \mathrm{PF}_{N 122}-(1-x) \mathrm{PF}_{N 212}+(1-x) \mathrm{PF}_{N 222}\right] \\
= & z(1-z)\left[-x\left(\mathrm{IN}_{1}-\mathrm{IN}_{2}+\mathrm{FN}_{1}+\mathrm{CN}\right)-\left(\mathrm{IN}_{2}+\mathrm{FN}_{2}+\mathrm{CN}\right)\right], \\
h_{z}= & (1-2 z)\left[x y \mathrm{PF}_{N 111}+x(1-y) \mathrm{PF}_{N 121}+(1-x) y \mathrm{PF}_{N 211}+(1-x)(1-y) \mathrm{PF}_{N 221}\right. \\
& \left.-x y \mathrm{PF} \mathrm{N}_{112}-x(1-y) \mathrm{PF}_{N 122}-(1-x) y \mathrm{PF}_{N 212}-(1-x)(1-y) \mathrm{PF}_{N 222}\right] \\
= & (1-2 z)\left[-x y\left(\mathrm{IN}_{1}-\mathrm{IN}_{2}+\mathrm{FN}_{1}+\mathrm{CN}\right)+x\left(\mathrm{IN}_{1}-\mathrm{IN}_{2}-\mathrm{CN}\right)-y\left(\mathrm{IN}_{2}+\mathrm{FN}_{2}+\mathrm{CN}\right)+\mathrm{IN}_{2}-\mathrm{IN}_{3}+\mathrm{LN}\right] .
\end{aligned}
$$

Let $f(x)=0, f(y)=0$, and $f(z)=0$. Then, it can obtain ten equilibrium points: $P_{1}(0,0,0), \quad P_{2}(0,0,1)$, $P_{3}(0,1,0), P_{4}(0,1,1), P_{5}(1,0,0), P_{6}(1,0,1), P_{7}(1,1,0)$, $P_{8}(1,1,1), \quad P_{9}\left(-\left(\mathrm{IG}_{0}+2 \mathrm{IG}_{1}-\mathrm{IG}_{2}-2 \mathrm{CG}+\mathrm{BG}_{2}+\mathrm{LG}_{2}+\right.\right.$ $\left.\mathrm{FG}_{2}\right) /\left(\mathrm{BG}_{1}-\mathrm{BG}_{2}+\mathrm{FG}_{1}-\mathrm{FG}_{2}+\mathrm{LG}_{1}-\mathrm{LG}_{2}\right),\left(\mathrm{IM}_{1}-\mathrm{IM}_{2}-\right.$ $\left.\left.\mathrm{CM}_{1}+\mathrm{CM}_{2}+\mathrm{LM}\right) /\left(\mathrm{FM}_{1}-\mathrm{FM}_{2}+\mathrm{FM}_{3}-\mathrm{FM}_{4}\right), 0\right)$, and $P_{10}$ $\left(\left(\mathrm{IG}_{1}-\mathrm{IG}_{2}+\mathrm{LG}_{2}-\mathrm{CG}\right) /\left(\mathrm{LG}_{2}-\mathrm{LG}_{1}\right),\left(\mathrm{BM}_{1}-\mathrm{BM}_{2}+\mathrm{IM}_{1}-\right.\right.$ $\left.\left.\mathrm{IM}_{2}-\mathrm{CM}_{1}+\mathrm{CM}_{2}+\mathrm{LM}\right) /\left(\mathrm{BM}_{1}-\mathrm{BM}_{2}+\mathrm{FM}_{1}-\mathrm{FM}_{2}\right), 1\right)$.

Let the equilibrium solution domain of the tripartite evolutionary game be $D=\{(x, y, x) \mid 0 \leq x \leq 1,0 \leq$ $y \leq 1,0 \leq z \leq 1\}$. Based on the definitions of $\mathrm{IG}_{1}$ and $\mathrm{CG}$, $\mathrm{IG}_{1}>\mathrm{CG}$ is reasonable and explicable. Because $\mathrm{IG}_{0}>\mathrm{IG}_{2}$, $\mathrm{BG}_{1}>\mathrm{BG}_{2}, \mathrm{FG}_{1}>\mathrm{FG}_{2}$, and $\mathrm{LG}_{1}>\mathrm{LG}_{2}$, we have $-\left(\mathrm{IG}_{0}+2 \mathrm{IG}_{1}-\mathrm{IG}_{2}-2 \mathrm{CG}+\mathrm{BG}_{2}+\mathrm{LG}_{2}+\mathrm{FG}_{2}\right) /\left(\mathrm{BG}_{1}-\mathrm{BG}_{2}\right.$ $\left.+\mathrm{FG}_{1}-\mathrm{FG}_{2}+\mathrm{LG}_{1}-\mathrm{LG}_{2}\right)<0$. Then, $P_{9}$ is not in $D$. Since the loss of the government is always larger than the cost of the government choosing $G_{1}$ when the network media choose $M_{1}$ and the government chooses the strategy $G_{2}$, there are $\mathrm{IG}_{1}-\mathrm{IG}_{2}+\mathrm{LG}_{1}-\mathrm{CG}$ and $\left(\mathrm{IG}_{1}-\mathrm{IG}_{2}+\mathrm{LG}_{2}-\mathrm{CG}\right) /\left(\mathrm{LG}_{2}\right.$ $\left.-\mathrm{LG}_{1}\right)>1$. Then, $P_{10}$ is not in $D$. Hence, for the ten equilibrium points, only $P_{1}, P_{2}, P_{3}, P_{4}, P_{5}, P_{6}, P_{7}$, and $P_{8}$ are in $D$.

Let $\operatorname{diag}\left(a_{1}, a_{2}, \ldots, a_{3}\right)$ be a diagonal matrix. For a matrix $A$, let $\operatorname{det} A$ and $\operatorname{tr}(A)$ represent the determinant and trace of the matrix, respectively. For each equilibrium point $P_{i}\left(x_{i}, y_{i}, z_{i}\right)$, if $\operatorname{det} J_{\left(x_{i}, y_{i}, z_{i}\right)}>0$ and $\operatorname{tr} J_{\left(x_{i}, y_{i}, z_{i}\right)}<0$, the equilibrium point $P_{i}\left(x_{i}, y_{i}, z_{i}\right)$ is evolutionary stable; if $\operatorname{det} J_{\left(x_{i}, y_{i}, z_{i}\right)}<0$ or $\operatorname{tr} J_{\left(x_{i}, y_{i}, z_{i}\right)}>0$, the equilibrium point $P_{i}\left(x_{i}, y_{i}, z_{i}\right)$ is not evolutionary stable. Thus, the asymptotic stabilities from $P_{1}$ to $P_{8}$ are analyzed as follows.

For the equilibrium point $P_{1}(0,0,0)$, we have

$$
J_{(0,0,0)}=\operatorname{diag}\left(\mathrm{PF}_{M 122}-\mathrm{PF}_{M 222}, \mathrm{PF}_{G 212}-\mathrm{PF}_{G 222}, \mathrm{PF}_{N 221}-\mathrm{PF}_{N 222}\right) \text {. }
$$

Then, det $J_{(0,0,0)}=\left(\mathrm{PF}_{M 122}-\mathrm{PF}_{M 222}\right)\left(\mathrm{PF}_{G 212}-\mathrm{PF}_{G 222}\right)$ $\left(\mathrm{PF}_{N 221}-\mathrm{PF}_{\mathrm{N} 222}\right), \operatorname{tr} J_{(0,0,0)}=\mathrm{PF}_{M 122}-\mathrm{PF}_{M 222}+\mathrm{PF}_{\mathrm{G} 212}-$ $\mathrm{PF}_{\mathrm{G} 222}+\mathrm{PF}_{\mathrm{N} 221}-\mathrm{PF}_{\mathrm{N} 222}$. For $\mathrm{PF}_{M 122}-\mathrm{PF}_{M 222}, \mathrm{PF}_{\mathrm{G} 212}$ $-\mathrm{PF}_{\mathrm{G} 222}$, and $\mathrm{PF}_{N 221}-\mathrm{PF}_{N 222}$, if they are all positive or negative, then we have $\operatorname{det} A>0$ and $\operatorname{tr} A>0$, or $\operatorname{det} A<0$ and $\operatorname{tr} A<0$, and so the equilibrium point $P_{1}(0,0,0)$ is not evolutionary stable; if one of them is positive, and two others are negative, then there exist two cases: (1) when the sum of absolute values of two negative items is larger than the positive one, we have $\operatorname{det} A>0$ and $\operatorname{tr} A>0$, and then, the equilibrium point $P_{1}(0,0,0)$ is evolutionary stable, and (2) when the sum of absolute values of two negative items is less than the positive one, we have $\operatorname{det} A>0$ and $\operatorname{tr} A>0$, and then, the equilibrium point $P_{1}(0,0,0)$ is not evolutionary stable; if one of them is negative, and two others are positive, we have $\operatorname{det} A>0$, and then, the equilibrium point $P_{1}(0,0,0)$ is not evolutionary stable.

For the equilibrium points $P_{2}(0,0,1), P_{3}(0,1,0)$, $P_{4}(0,1,1), P_{5}(1,0,0), P_{6}(1,0,1), P_{7}(1,1,0)$, and $P_{8}(1,1,1)$, we have the following:

$$
\begin{aligned}
& J_{(0,0,1)}=\operatorname{diag}\left(\mathrm{PF}_{M 121}-\mathrm{PF}_{M 221}, \mathrm{PF}_{G 211}-\mathrm{PF}_{G 221}, \mathrm{PF}_{N 222}-\mathrm{PF}_{N 221}\right), \\
& J_{(0,1,0)}=\operatorname{diag}\left(\mathrm{PF}_{M 112}-\mathrm{PF}_{M 212}, \mathrm{PF}_{G 222}-\mathrm{PF}_{G 212}, \mathrm{PF}_{N 211}-\mathrm{PF}_{N 212}\right), \\
& J_{(0,1,1)}=\operatorname{diag}\left(\mathrm{PF}_{M 111}-\mathrm{PF}_{M 211}, \mathrm{PF}_{G 221}-\mathrm{PF}_{G 211}, \mathrm{PF}_{N 212}-\mathrm{PF}_{N 211}\right), \\
& J_{(1,0,0)}=\operatorname{diag}\left(\mathrm{PF}_{M 222}-\mathrm{PF}_{M 122}, \mathrm{PF}_{G 112}-\mathrm{PF}_{G 122}, \mathrm{PF}_{N 121}-\mathrm{PF}_{N 122}\right),
\end{aligned}
$$




$$
\begin{aligned}
& J_{(1,0,1)}=\operatorname{diag}\left(\mathrm{PF}_{M 221}-\mathrm{PF}_{M 121}, \mathrm{PF}_{G 111}-\mathrm{PF}_{G 121}, \mathrm{PF}_{N 122}-\mathrm{PF}_{N 121}\right), \\
& J_{(1,1,0)}=\operatorname{diag}\left(\mathrm{PF}_{M 212}-\mathrm{PF}_{M 112}, \mathrm{PF}_{G 122}-\mathrm{PF}_{G 112}, \mathrm{PF}_{N 112}-\mathrm{PF}_{N 111}\right), \\
& J_{(1,1,1)}=\operatorname{diag}\left(\mathrm{PF}_{M 211}-\mathrm{PF}_{M 111}, \mathrm{PF}_{G 121}-\mathrm{PF}_{G 111}, \mathrm{PF}_{N 112}-\mathrm{PF}_{N 111}\right) .
\end{aligned}
$$

Similar to the above discussion of the equilibrium point $P_{1}(0,0,0)$, the stabilities of the remaining equilibrium points are as follows. For $\left[\mathrm{PF}_{M 121}-\mathrm{PF}_{M 221}\right.$, $\mathrm{PF}_{G 211}-\mathrm{PF}_{G 221}$ and $\left.\mathrm{PF}_{N 222}-\mathrm{PF}_{N 221}\right], \quad\left[\mathrm{PF}_{M 112}-\mathrm{PF}_{M 212}\right.$, $\mathrm{PF}_{\mathrm{G} 222}-\mathrm{PF}_{\mathrm{G} 212}$ and $\left.\mathrm{PF}_{\mathrm{N} 211}-\mathrm{PF}_{\mathrm{N} 212}\right], \quad\left[\mathrm{PF}_{M 111}-\mathrm{PF}_{M 211}\right.$, $\mathrm{PF}_{G 221}-\mathrm{PF}_{G 211}$ and $\left.\mathrm{PF}_{N 212}-\mathrm{PF}_{N 211}\right], \quad\left[\mathrm{PF}_{M 222}-\mathrm{PF}_{M 122}\right.$, $\mathrm{PF}_{G 112}-\mathrm{PF}_{G 122}$ and $\left.\mathrm{PF}_{\mathrm{N} 121}-\mathrm{PF}_{\mathrm{N} 122}\right], \quad\left[\mathrm{PF}_{\mathrm{M} 221}-\mathrm{PF}_{M 121}\right.$, $\mathrm{PF}_{G 111}-\mathrm{PF}_{G 121}$ and $\left.\mathrm{PF}_{N 122}-\mathrm{PF}_{N 121}\right], \quad\left[\mathrm{PF}_{M 212}-\mathrm{PF}_{M 112}\right.$, $\mathrm{PF}_{G 122}-\mathrm{PF}_{G 112}$ and $\left.\mathrm{PF}_{N 112}-\mathrm{PF}_{N 111}\right]$, and $\left[\mathrm{PF}_{M 211}-\right.$ $\mathrm{PF}_{M 111}, \mathrm{PF}_{G 121}-\mathrm{PF}_{G 111}$ and $\mathrm{PF}_{N 112}-\mathrm{PF}_{N 111}$, if they (the items in a symbol "[]") are all positive or negative, then the equilibrium points $P_{2}(0,0,1), \quad P_{3}(0,1,0), \quad P_{4}(0,1,1)$, $P_{5}(1,0,0), P_{6}(1,0,1), P_{7}(1,1,0)$, and $P_{8}(1,1,1)$ are not evolutionary stable; if one of them is positive and two others are negative, then $P_{2}(0,0,1), P_{3}(0,1,0), P_{4}(0,1,1)$, $P_{5}(1,0,0), P_{6}(1,0,1), P_{7}(1,1,0)$, and $P_{8}(1,1,1)$ are evolutionary stable while the sum of absolute values of two negative items is larger than the positive one and are not evolutionary stable while the sum of absolute values of two negative items is less than the positive one; and if one of them is negative, and two others are positive, then the equilibrium points $P_{2}(0,0,1), \quad P_{3}(0,1,0), \quad P_{4}(0,1,1)$, $P_{5}(1,0,0), P_{6}(1,0,1), P_{7}(1,1,0)$, and $P_{8}(1,1,1)$ are not evolutionary stable.

\section{Experiment}

To facilitate the quantification of parameters on the tripartite evolutionary game model, we exploit the same value functions and decision (probability) weighting functions [36] to characterize (initial) incomes, costs, profits, bonuses, losses, fines, and decision probabilities. To simplify the following experiments, the (initial) incomes, bonus, and profits are measured by the value function:

$$
V(x)=\left\{\begin{array}{l}
\left(x-U_{0}\right)^{\theta}, \quad x \geq U_{0}, \\
-\lambda\left(U_{0}-x\right)^{\beta}, \quad x<U_{0},
\end{array}\right.
$$

where $\beta=0.88, \theta=0.88, \lambda=2 ; U_{0} \in[-1,1]$ is the reference point.

The costs, losses, and fines in the game are characterized by the value function:

$$
Z(x)= \begin{cases}\delta\left(x-U_{1}\right)^{\phi}, & x \geq U_{1}, \\ -\left(U_{1}-x\right)^{\sigma}, & x<U_{1},\end{cases}
$$

where $\delta=2, \phi=0.98, \sigma=0.98 ; U_{1} \in[0,1]$ is the reference point.

The decision probabilities choosing the strategies $M_{1}$, $G_{1}$, and $N_{1}$ in the game are calculated by the decision (probability) weighting function:

$$
\pi(\epsilon)=\frac{\epsilon^{\Gamma}}{\left[\epsilon^{\Gamma}+(1-\epsilon)^{\Gamma}\right]^{1 / \Gamma}},
$$

where $\Gamma=0.75$.

In the following experiments, for the reference point $U_{0}$ $\left(U_{1}\right.$, respectively), we randomly generate 50 data, which satisfied the uniform distribution in $[-1,1]([0,1]$, respectively), and take their average value as the reference point. When one influence parameter is considered, other parameters are set as follows: (1) the decision probabilities are set as 0.5 ; (2) the values of initial incomes, bonuses, and profits are set as 0 ; and (3) the values of costs, losses, and fines are set as 0.5 .

Next, the expected payoffs of the network media, government, and netizen for misinformation propagation in the tripartite evolutionary game model are discussed based on the decision probabilities, (initial) incomes, profits, bonuses, costs, losses, and fines, respectively. In Figure 2, the expected payoffs of the network media, government, and netizen for misinformation propagation change with the values of decision probabilities, i.e., $x, y$, and $z$ in $[0,1]$, respectively. When we analyze parameter $x$ (resp. $y$ or $z$ ), we generated 50 random numbers $x$ (resp. $y$ or $z$ ), which satisfy the uniform distribution in $[0,1]$, and the rest of the other parameters remain unchanged according to the default settings.

It shows that the expected payoffs EM and EG increase when the probabilities of choosing $M_{1}$ and $G_{1}$ rise, respectively. However, the expected payoff EN decreases when the probabilities of choosing $N_{1}$ increase. These results show that if the decision probabilities of the network media and government that they, respectively, choose the "promoting misinformation" and "supervision" strategies increase, their payoffs rise continuously. On the contrary, the payoff of the netizen drops quickly, while the decision probability of choosing the "spread" strategy increases.

In Figure 3, the expected payoffs of the network media for misinformation propagation change with (initial) incomes, profits, bonuses, costs, losses, and fines, respectively. The values of $\mathrm{IM}_{0}, \mathrm{IM}_{1}, \mathrm{IM}_{2}, \mathrm{BM}_{1}$, and $\mathrm{BM}_{2}$ belong to $[-1,1]$. The values of $\mathrm{CM}_{1}, \mathrm{CM}_{2}, \mathrm{LM}, \mathrm{FM}_{1}, \mathrm{FM}_{2}, \mathrm{FM}_{3}$, and $\mathrm{FM}_{4}$ belong to $[0,1]$. The experimental results show that as the values of $\mathrm{IM}_{0}, \mathrm{IM}_{1}, \mathrm{IM}_{2}, \mathrm{BM}_{1}$, and $\mathrm{BM}_{2}$ increase, the expected payoff EM increases; and as the values of $\mathrm{CM}_{1}$, $\mathrm{CM}_{2}, \mathrm{LM}, \mathrm{FM}_{1}, \mathrm{FM}_{2}, \mathrm{FM}_{3}$, and $\mathrm{FM}_{4}$ increase, the expected payoff slowly decreases. It also shows that the lower the value of $\mathrm{IM}_{0}$ is, the lower the expected payoff is; the lower the values of $\mathrm{LM}$ and $\mathrm{CM}_{1}$ are, the higher the expected payoffs are. This phenomenon means that to increase the expected payoff of network media, it is necessary to increase the initial income. In particular, to improve the expected payoff of network media, when the network media choose $M_{2}$, the network media can increase the advertisements, click rate, netizen, and popularity. When the network media choose 


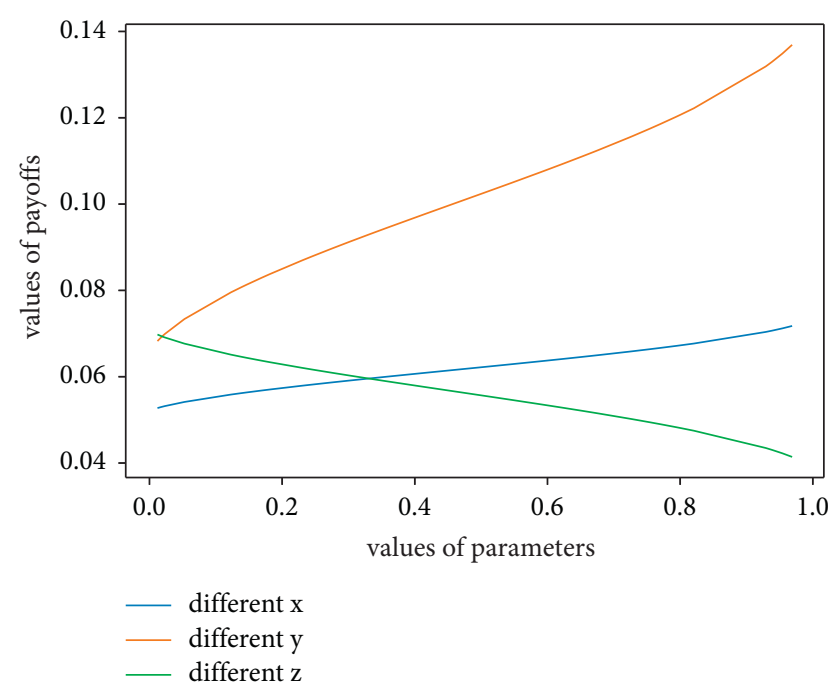

Figure 2: Impacts of different decision probabilities on expected payoffs.

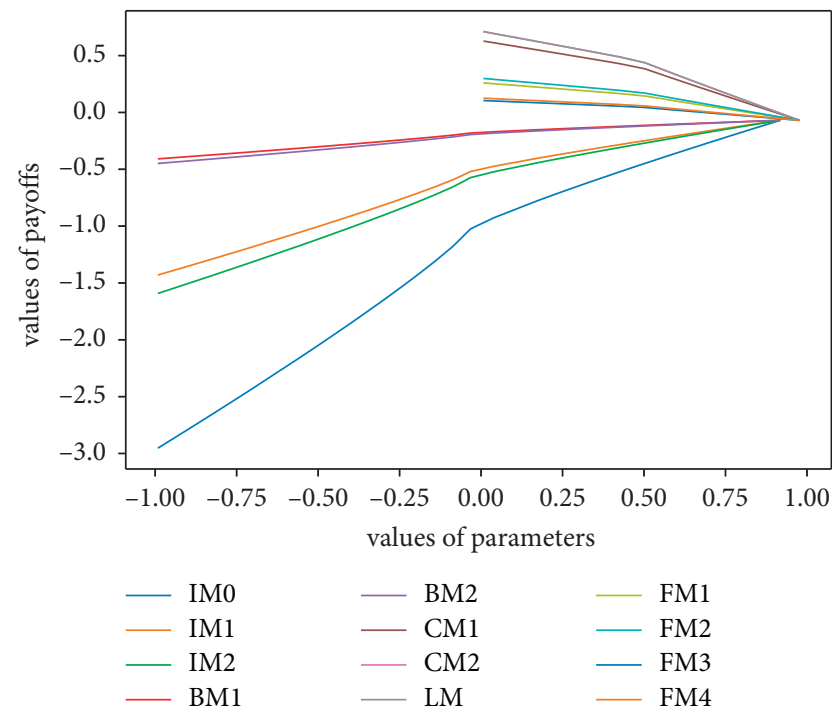

FIGURE 3: Impacts of different parameters on the expected payoffs of the network media.

$M_{1}$, the network media can decrease the cost from manpower, material resources, etc.

In Figure 4, the expected payoffs of the government for misinformation propagation change with (initial) incomes, profits, bonuses, costs, losses, and fines, respectively. The values of $\mathrm{IG}_{0}, \mathrm{IG}_{1}, \mathrm{IG}_{2}, \mathrm{BG}_{1}$, and $\mathrm{BG}_{2}$ belong to $[-1,1]$. The values of $C G, \mathrm{LG}_{1}, \mathrm{LG}_{2}, \mathrm{FG}_{1}$, and $\mathrm{FG}_{2}$ belong to $[0,1]$. The experimental results show that as the values of $\mathrm{IG}_{0}, \mathrm{IG}_{1}, \mathrm{IG}_{2}$, $B G_{1}$, and $B G_{2}$ increase, the expected payoffs steadily go up, whereas the values of $\mathrm{CG}, \mathrm{LG}_{1}, \mathrm{LG}_{2}, \mathrm{FG}_{1}$, and $\mathrm{FG}_{2}$ increase, expected payoffs continuously decrease. They also show that the lower the value of $\mathrm{IG}_{0}$ is, the lower the expected payoff is; and the lower the value of CG is, the higher the expected payoff is. It concludes that if the government intends to increase its expected payoff, when the government chooses $G_{1}$, it can increase the initial income; and if the government

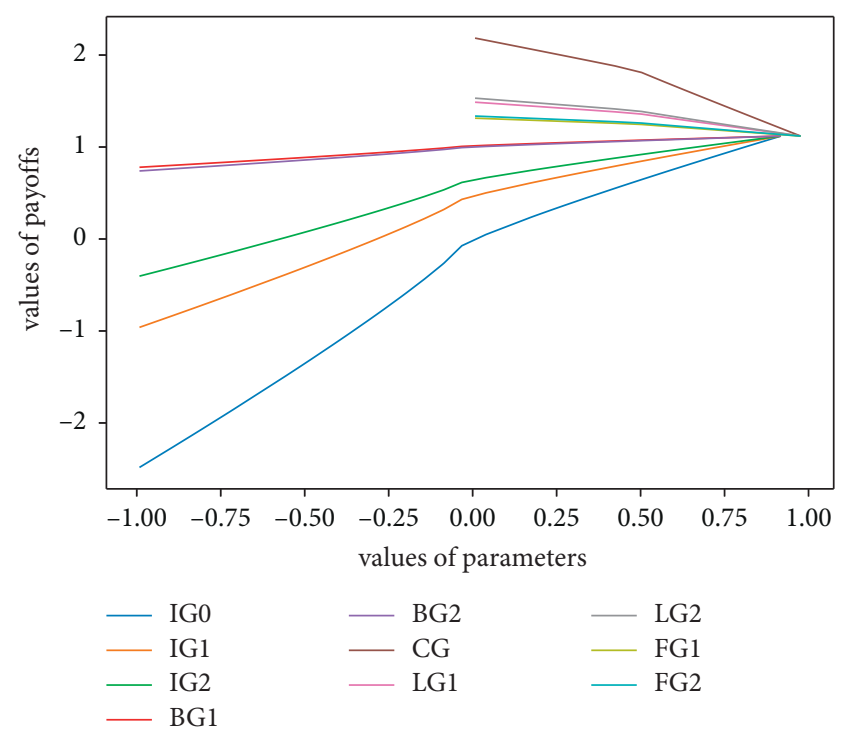

FIGURE 4: Impact of different parameters on the expected payoff of the government.

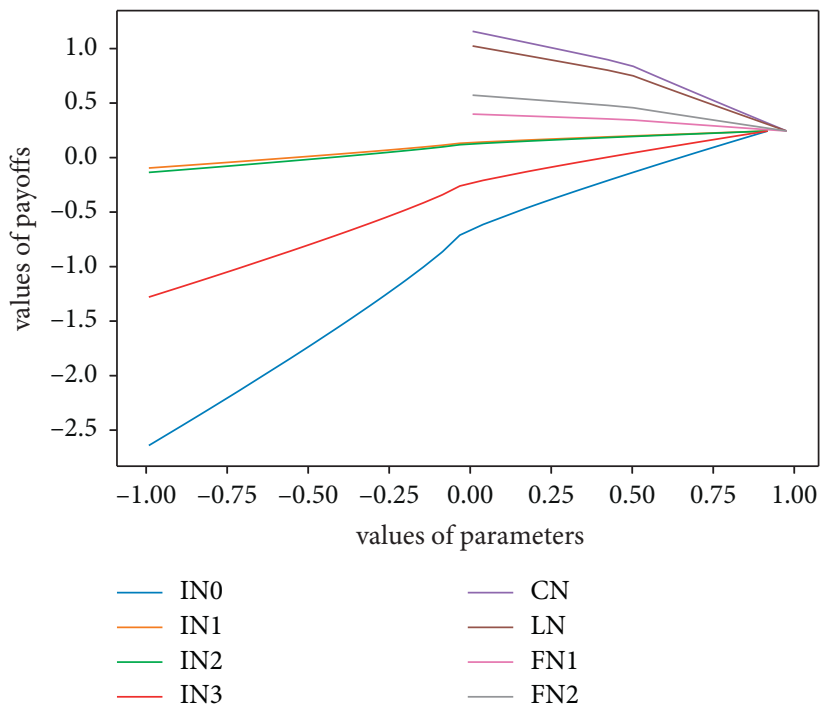

FIGURE 5: Impacts of different parameters on the expected payoffs of the netizen.

chooses $G_{2}$, it can decrease the cost from manpower, material resources, etc.

In Figure 5, the expected payoffs of the netizen for misinformation propagation change with (initial) incomes, profits, costs, losses, and fines, respectively. The values of $\mathrm{IN}_{0}, \mathrm{IN}_{1}, \mathrm{IN}_{2}$, and $\mathrm{IN}_{3}$ belong to $[-1,1]$. The values of $\mathrm{CN}$, $\mathrm{LN}, \mathrm{FN}_{1}$, and $\mathrm{FN}_{2}$ belong to $[0,1]$. The experimental results show that as the values of $\mathrm{IN}_{0}, \mathrm{IN}_{1}, \mathrm{IN}_{2}$, and $\mathrm{IN}_{3}$ increase, the expected payoffs increase; and as the values of $\mathrm{CN}, \mathrm{LN}, \mathrm{FN}_{1}$, and $\mathrm{FN}_{2}$ increase, the expected payoffs quickly reduce. The results also show that the lower the value of $\mathrm{IN}_{0}$ is, the lower the expected payoff is; the lower the values of $\mathrm{CN}$ and $\mathrm{LN}$ are, the higher the expected payoffs are. This phenomenon means that if the netizen wants to promote the expected payoff of the netizen, the netizen can increase the initial 
income. That is, if the netizen expects to increase its expected payoff, when the netizen chooses $N_{1}$, it can decrease the cost from manpower, material resources, etc. When the netizen chooses $N_{2}$, it can increase the attention, followers, etc.

Based on the above discussion, the expected payoffs of the players in the proposed tripartite evolutionary game model for misinformation propagation are influenced by different parameters including (initial) incomes, profits, bonuses, costs, losses, and fines. If one player intends to increase its expected payoff, then it can choose a proper strategy and can select various measures to change the values of different parameters, maximizing the expected payoff of the player.

\section{Conclusion}

This study established a tripartite evolutionary game model for misinformation propagation. This model considered three players, i.e., network media, government, and netizen. Various parameters, such as (initial) incomes, profits, bonuses, costs, losses, and fines, are proposed for three players. The expected payoffs of the players are derived in detail. By evolutionary replication dynamic equations, the evolutionary stable strategies for the proposed model are proved theoretically. Finally, some experiments are made to find the influences of different parameters on the proposed game model. To increase the expected payoffs of network media, government, and netizen, if the network media, government, and netizen choose "promoting misinformation," "nonsupervision," and "spread," respectively, the network media, government, and netizen can decrease manpower, material resources, and so on. If the network media choose "blocking misinformation propagation," the network media can increase the advertisements, click rate, netizen, and popularity. If the government chooses "supervision," it can increase the initial income. If the netizen chooses "non-spread," it can increase the attention, followers, etc. In future, the experiments of the tripartite evolutionary game model on real misinformation dataset and the new evolutionary game model for misinformation propagation are both worthy of study carefully.

\section{Data Availability}

Data sharing is not applicable to this article as no datasets were generated.

\section{Conflicts of Interest}

Sichuan Suitang Science and Technology Co., Ltd. was affiliated with this study. The authors declare that there are no conflicts of interest.

\section{Authors' Contributions}

The authors claim that the research was realized in collaboration with the same responsibility. All authors read and approved the last version of the manuscript.

\section{Acknowledgments}

This work was partially supported by the National Natural Science Foundation of China (Nos. 61802 316, 61872 298, and 61902324 ), Chunhui Plan Cooperation and Research Project, Ministry of Education of China (Nos. Z2015109 and Z2015100), "Young Scholars Reserve Talents" program of Xihua University, Science and Technology Department of Sichuan Province (Nos. 22ZDYF3157 and 2021YFQ0008), Key Scientific Research Fund of Xihua University (No. z1422615), and Innovation Fund of Postgraduate, Xihua University (Nos. YCJJ2021025, YCJJ2021031, and YCJJ2021124), and Opening Project of Intelligent Policing Key Laboratory of Sichuan Province (No. ZNJW2022ZZZD003).

\section{References}

[1] H. Zhang, M. A. Alim, X. Li, M. T. Thai, and H. T. Nguyen, "Misinformation in online social networks: detect them all with a limited budget," ACM Transactions on Information Systems, vol. 34, no. 3, p. 18, 2016.

[2] C. V. Pham, M. T. Thai, H. V. Duong, B. Q. Bui, and H. X. Hoang, "Maximizing misinformation restriction within time and budget constraints," Journal of Combinatorial Optimization, vol. 35, no. 4, pp. 1202-1240, 2018.

[3] Z. Tan, D. Wu, T. Gao, I. You, and V. Sharma, "AIM: activation increment minimization strategy for preventing bad information diffusion in OSNs," Future Generation Computer Systems, vol. 94, pp. 293-301, 2019.

[4] W. Liu, X. Wu, W. Yang, X. Zhu, and S. Zhong, "Modeling cyber rumor spreading over mobile social networks: a compartment approach," Applied Mathematics and Computation, vol. 343, no. 4, pp. 214-229, 2019.

[5] G. Shrivastava, P. Kumar, R. P. Ojha, P. K. Srivastava, S. Mohan, and G. Srivastava, "Defensive modeling of fake news through online social networks," IEEE Transactions on Computational Social Systems, vol. 7, no. 5, pp. 1159-1167, 2020.

[6] C. Wang, G. Wang, X. Luo, and H. Li, "Modeling rumor propagation and mitigation across multiple social networks," Physica A: Statistical Mechanics and its Applications, vol. 535, Article ID 122240, 2019.

[7] M. Jiang, Q. Gao, and J. Zhuang, "Reciprocal spreading and debunking processes of online misinformation: a new rumor spreading-debunking model with a case study," Physica A: Statistical Mechanics and its Applications, vol. 565, Article ID 125572, 2021.

[8] M. A. Manouchehri, M. S. Helfroush, and H. Danyali, "A theoretically guaranteed approach to efficiently block the influence of misinformation in social networks," IEEE Transactions on Computational Social Systems, vol. 8, no. 3, pp. 716-727, 2021.

[9] C. Wang, Y. Zhang, Q. Shi, Y. Feng, and C. Chen, "Efficient influence spread management via budget allocation at community scale," Expert Systems with Applications, vol. 175, Article ID 114814, 2021.

[10] A. Zareie and R. Sakellariou, "Minimizing the spread of misinformation in online social networks: a survey," Journal of Network and Computer Applications, vol. 186, Article ID 103094, 2021

[11] R. Aswani, A. K. Kar, and P. V. Ilavarasan, "Experience: managing misinformation in social media-insights for 
policymakers from twitter analytics," Journal of Data and Information Quality, vol. 12, no. 1, pp. 1-18, 2020.

[12] M. Glenski, T. Weninger, and S. Volkova, "Propagation from deceptive news sources who shares, how much, how evenly, and how quickly?" IEEE Transactions on Computational Social Systems, vol. 5, no. 4, pp. 1071-1082, 2018.

[13] A. K. Kar and R. Aswani, "How to differentiate propagators of information and misinformation-Insights from social media analytics based on bio-inspired computing," Journal of Information and Optimization Sciences, vol. 42, no. 6, pp. 1307-1335, 2021.

[14] S. Chen, L. Xiao, and J. Mao, "Persuasion strategies of misinformation-containing posts in the social media," Information Processing and Management, vol. 58, no. 5, Article ID 102665, 2021.

[15] G. K. Shahi, A. Dirkson, and T. A. Majchrzak, "An exploratory study of COVID-19 misinformation on Twitter," Online Social Networks and Media, vol. 22, Article ID 100104, 2021.

[16] M. Liu and L. Rong, "An online multi-dimensional opinion dynamic model with misinformation diffusion in emergency events," Journal of Information Science, 2021.

[17] N. Abuzainab and W. Saad, "A multiclass mean-field game for thwarting misinformation spread in the internet of battlefield things," IEEE Transactions on Communications, vol. 66, no. 12 , pp. 6643-6658, 2018.

[18] Y. Wang, M. McKee, A. Torbica, and D. Stuckler, "Systematic literature review on the spread of health-related misinformation on social media," Social Science and Medicine, vol. 240, Article ID 112552, 2019.

[19] Y. Xiao, C. Song, and Y. Liu, "Social hotspot propagation dynamics model based on multidimensional attributes and evolutionary games," Communications in Nonlinear Science and Numerical Simulation, vol. 67, pp. 13-25, 2019.

[20] Q. Li, C. Song, B. Wu, Y. Xiao, and B. Wang, "Social hotspot propagation dynamics model based on heterogeneous mean field and evolutionary games," Physica A: Statistical Mechanics and its Applications, vol. 508, pp. 324-341, 2018.

[21] J. Wang, X. Wang, and L. Fu, "Evolutionary game model of public opinion information propagation in online social networks," IEEE Access, vol. 8, Article ID 127732, 2020.

[22] F. Xiong, X. Wang, S. Pan, H. Yang, H. Wang, and C. Zhang, "Social recommendation with evolutionary opinion dynamics," IEEE Transactions on Systems, Man, and Cybernetics: Systems, vol. 50, no. 10, pp. 3804-3816, 2020.

[23] X. Yang, Z. Zhu, H. Yu, Y. Zhao, and L. Guo, "Evolutionary Game Dynamics of the Competitive Information Propagation on Social Networks," Complexity, vol. 2019, Article ID 8385426, 11 pages, 2019.

[24] J. Lv, W. Yao, Y. Wang, Z. Wang, and J. Yu, “A game model for information dissemination in live streaming e-commerce environment," International Journal of Communication Systems, vol. 35, no. 18, 2021.

[25] Y. Zhang, L. Wang, J. J. H. Zhu, and X. Wang, "Conspiracy vs science: a large-scale analysis of online discussion cascades," World Wide Web, vol. 24, no. 2, pp. 585-606, 2021.

[26] X. Wang, Y. Wu, Y. Ren, R. Feng, N. Yu, and J. Wan, “An evolutionary game-based trust cooperative stimulation model for large scale MANETs," International Journal of Distributed Sensor Networks, vol. 9, no. 6, Article ID 245017, 2013.

[27] Y. Xiao, D. Chen, S. Wei, Q. Li, H. Wang, and M. Xu, "Rumor propagation dynamic model based on evolutionary game and anti-rumor," Nonlinear Dynamics, vol. 95, no. 1, pp. 523-539, 2019.
[28] Y. Xiao, Q. Yang, C. Sang, and Y. Liu, "Rumor diffusion model based on representation learning and anti-rumor," IEEE Transactions on Network and Service Management, vol. 17, no. 3, pp. 1910-1923, 2020.

[29] M. Askarizadeh, B. T. Ladani, and M. H. Manshaei, "An evolutionary game model for analysis of rumor propagation and control in social networks," Physica A: Statistical Mechanics and its Applications, vol. 523, pp. 21-39, 2019.

[30] M. Askarizadeh and B. Tork Ladani, "Soft rumor control in social networks: modeling and analysis," Engineering Applications of Artificial Intelligence, vol. 100, Article ID 104198, 2021.

[31] H. Zhang, Y. Li, Y. Chen, and H. V. Zhao, "Smart evolution for information diffusion over social networks," IEEE Transactions on Information Forensics and Security, vol. 16, pp. 1203-1217, 2021.

[32] X. Gao, S. Feng, D. Niyato, P. Wang, K. Yang, and Y. C. Liang, "Dynamic access point and service selection in backscatterassisted RF-powered cognitive networks," IEEE Internet of Things Journal, vol. 6, no. 5, pp. 8270-8283, 2019.

[33] M. Alam, Y. Ida, and J. Tanimoto, "Abrupt epidemic outbreak could be well tackled by multiple pre-emptive provisions-A game approach considering structured and unstructured populations," Chaos, Solitons and Fractals, vol. 143, Article ID 110584, 2021.

[34] H. Huang, T. Wang, M. Hu, M. Dong, and L. Lai, "Node attitude aware information dissemination model based on evolutionary game in social networks," Mobile Networks and Applications, vol. 26, no. 1, pp. 114-129, 2021.

[35] M. L. Manapat and D. G. Rand, "Delayed and inconsistent information and the evolution of trust," Dynamic Games and Applications, vol. 2, no. 4, pp. 401-410, 2012.

[36] B. Wu, J. Cheng, and Y. Qi, "Tripartite evolutionary game analysis for "Deceive acquaintances" behavior of e-commerce platforms in cooperative supervision," Physica A: Statistical Mechanics and its Applications, vol. 550, Article ID 123892, 2020. 